\title{
BCS Health Informatics Scotland (HIS)
}

\author{
Glasgow, UK \\ 2 - 3 September 2014
}

Editors

Dr Matt-Mouley Bouamrane 


\section{Abstract}

The BCS HIS conference is the largest eHealth / Health Informatics conference in Scotland. A key feature of our conference is that we have an excellent mix of speakers from Government, the NHS, industry exhibitors and academics from all the main universities of Scotland. Having successfully introduced a research track since the 2012 conference, we are now proud to publish for the first time conference proceedings in the BCS Electronic Workshops in Computing, eWiC, with a conference special issue to follow shortly (Health Informatics journal). 


\section{Full Synopsis}

The BCS Health Informatics Scotland (HIS) took place on 2-3rd of September 2014 in the Grand Central hotel in Glasgow. The BCS HIS conference is the largest eHealth / Health Informatics conference in Scotland. A key feature of our conference is that we have an excellent mix of speakers from Government, the NHS, industry exhibitors and academics from all the main universities of Scotland. Having successfully introduced a research track since the 2012 conference, we are now proud to publish for the first time conference proceedings in the BCS Electronic Workshops in Computing, eWiC, with a conference special issue to follow shortly (Health Informatics journal).

In addition to the research track, the 2014 conference themes were: Clinical Quality and eHealth, Health and Social Care Integration and Business Analytics for health management. The reader of the proceedings will see that the proceedings provide a good overview of these conference topics. We had several submission categories and this is also reflected in the proceedings, which include a selection of full research papers, position papers, extended abstract and work in progress papers as well as workshop summaries. The research published in the proceedings span across Scottish Universities and the NHS, including submission from National Service Scotland, the University of Aberdeen, the University of Dundee, the University of Edinburgh, Edinburgh Napier University, the University of Glasgow, the University of Strathclyde and Glasgow Caledonian University.

Information on BCS Health Scotland is available on http://www.scotshi.bcs.org.uk/ 


\section{Editors}

This conference was edited by:

Dr Matt-Mouley Bouamrane joined General Practice and Primary Care in February 2010 as a CSO Research Fellow in Health Informatics and the Health Services Research, working with Professor Frances Mair on the development of information systems for the integration across primary and secondary care in Scotland of the preoperative assessment of patients prior to surgery.

He graduated as a Bachelor of Electronic Engineering at the Université de Paris-XI, Orsay, followed by a postgraduate diploma in computer engineering (2003) and a PhD in computer science (2006) at the University of Dublin, Trinity College, where he was a member of the Artificial Intelligence Group (AIG). His doctoral research consisted of developing information access and retrieval methods and systems for remote web-based meetings in collaboration with Dr Saturnino Luz.

From 2007 until 2010, Dr Bouamrane was a postdoctoral researcher at the University of Manchester within the bio-informatics group of Professor Alan Rector in a knowledge transfer project, working on the development of a knowledge-based preoperative decision support system in partnership with a Scottish SME, Informatics-CIS.

\section{BCS Health Informatics Scotland Conference Committee}

Dr Matt-Mouley Bouamrane (Conference Chair), Lecturer in eHealth, Computer and Information Sciences, University of Strathclyde

Paul Woolman, (Conference Chair), Information Services Manager at NHS Forth Valley

Jackie Caldwell, NHS National Services Scotland

Gillian Flett, Information \& eLearning Manager at NHS Education for Scotland

Sharon Levy, Lecturer in Distance Education, University of Edinburgh

Angus McCann, Healthcare Industry Consultant, at IBM (EMEA)

Lachlan MacPherson, NHS Western Isles

Margaret Moore, NHS

Andrew Turner, Head of Information Assurance and Security NHS Dumfries \& Galloway 
Janice Watson, NHS National Services Scotland

Mario Kolberg, Senior Lecturer, Computing Science and Mathematics, University of Stirling

Marilyn Mcgee-Lennon, Senior Lecturer $\mathrm{HCl}$, Computer and Information Sciences, University of Strathclyde

Mark McGilchrist, Senior Research Fellow, Health Informatics Centre, University of Dundee

Alasdair Mort, Research Fellow, Centre for Rural Health, University of Aberdeen

Maria Wolters, Research Fellow, School of Informatics, University of Edinburgh 


\section{Papers:}

\section{Full Papers}

Wilfred Bonney, Donald Scobbie, Thomas Nind, Sindy Donaldson-Buist, Christopher Hall \& Emily Jefferson Profiling Clinical Datasets for Data Quality Assessment and Improvement http://dx.doi.org/10.14236/ewic/HIS2014.1

Dimitra Gkatzia, Verena Rieser, Alexander McSporran, Alistair McGowan, Alasdair Mort \& Michaela Dewar Generating Verbal Descriptions from Medical Sensor Data: A Corpus Study on User Preferences http://dx.doi.org/10.14236/ewic/HIS2014.2

Derek Sleeman, Laura Moss \& John Kinsella Temporal Discovery Workbench: a Case Study with ICU Patient Datasets $\quad$ http://dx.doi.org/10.14236/ewic/HIS2014.3

Ruth Agbakoba, Marilyn McGee-Lennon, Matt-Mouley Bouamrane, Nick Watson \& Frances S. Mair Delivering Innovative eHealth Services at Scale: Implementers' Views on Achieving 'Buy-In' http://dx.doi.org/10.14236/ewic/HIS2014.4

\section{Short \& Position Papers}

Mark M McGilchrist Towards Safer Methods of Electronic Surveillance http://dx.doi.org/10.14236/ewic/HIS2014.5

Grzegorz Spyra, William J Buchanan \& Elias Ekonomou Distributed, Highly-Scalable, Sticky Policies Implementation for Healthcare http://dx.doi.org/10.14236/ewic/HIS2014.6

\section{Extended Abstracts \& Work-in-Progress Papers}

Petros Papapanagiotou, Jacques Fleuriot, Areti Manataki, Andrew Winter, Rak Nandwani, Daniel Clutterbuck \& David Wilks Rigorous development of computer based Integrated Care Pathways for HIV patients $\quad$ http://dx.doi.org/10.14236/ewic/HIS2014.7

Siobhan O'Connor, Marilyn McGee-Lennon, Matt-Mouley Bouamrane, Frances S Mair \& Kate O'Donnell Barriers to Recruiting and Engaging End-Users in Large-Scale Digital Health \& Wellbeing Technologies and Services $\quad$ http://dx.doi.org/10.14236/ewic/HIS2014.8 
Alison M. Devlin, Marilyn McGee-Lennon, Catherine O' Donnell \& Frances Mair Charting Complex Change: Application of the e-Health Implementation Toolkit (e-HIT) in 'dallas' http://dx.doi.org/10.14236/ewic/HIS2014.9

Dilip Nathwani, Marion Bennie, William Malcolm, Ken Monaghan, Charis Marwick \& Emese Toth The NHS Infection Intelligence Platform $\quad$ http://dx.doi.org/10.14236/ewic/HIS2014.10

\section{Workshop Summaries}

Leila Eadie, Alasdair Mort \& Philip Wilson Technology to Support Rural Health and Well-being http://dx.doi.org/10.14236/ewic/HIS2014.11

Marilyn McGee-Lennon \& Lynne Baillie The SICSA Workshop Series on Technologies for Health and Wellness (THAW) http://dx.doi.org/10.14236/ewic/HIS2014.12 